\title{
Endoscopic Microvascular Decompression: A Stepwise Operative Technique
}

\author{
Shih-Shan Lang H. Isaac Chen John Y.K. Lee \\ Department of Neurosurgery, University of Pennsylvania, Philadelphia, Pa., USA
}

\section{Key Words}

Trigeminal neuralgia - Microvascular decompression •

Endoscopic $\cdot$ Hemifacial spasm

\begin{abstract}
Background/Aims: Microvascular decompression (MVD) of the trigeminal nerve is a widely accepted treatment for patients with trigeminal neuralgia caused by vascular compression. The neuroendoscope is rapidly becoming a complementary tool in minimally invasive neurosurgery of the ventral anterior skull base. Its adoption in the lateral approach to the posterior fossa has been slower and has been used primarily as an adjunct to conventional microscopic surgical techniques, e.g. endoscope-assisted microsurgery. Methods: In this paper, we describe a stepwise, technical commentary on a purely endoscopic MVD of the trigeminal nerve via the retrosigmoid route. Results: From our experience, the endoscope provides excellent visualization of the neurovascular relationship. By allowing full visualization of the trigeminal nerve, endoscopy may likely lead to an increase in the number of successful MVDs and a decrease in the number of complications. Conclusion: We believe endoscopic MVD is a safe and effective method of accessing the trigeminal nerve in the cerebellopontine angle and of performing MVD. This endoscopic technique can be implemented in other neurosurgical and neuro-otological procedures such as resection of cerebellopontine angle masses.
\end{abstract}

Copyright $\odot 2012$ S. Karger AG, Basel

\section{KARGER}

Fax +41613061234

E-Mail karger@karger.ch

www.karger.com
(C) 2012 S. Karger AG, Basel

0301-1569/12/0746-0293\$38.00/0

Accessible online at:

www.karger.com/orl

\section{Introduction}

In the 1920s, Walter Dandy $[1,2]$ first hypothesized that trigeminal neuralgia (tic douloureux) could be caused by vascular compression of the trigeminal nerve at its pontine origin in the cerebellopontine angle (CPA). In the 1950s, Gardner and Miklos [3] extended this approach into what is now known as microvascular decompression (MVD). However, it was not until the 1970s that Peter Jannetta [4] popularized and mainstreamed this surgery. In the 1990s, MVD was modified by introducing the endoscope as supplementary instrument, e.g. endoscope-assisted microsurgery [5]. We hypothesized that a fully endoscopic procedure would provide an unobstructed panoramic view of the CPA [6-8], allowing for a less traumatic, minimally invasive approach to the site of vascular pathology $[7,9]$.

The endoscope has quickly become a standard operative tool in minimally invasive neurosurgery of the sella and ventral anterior skull base $[10,11]$. The use of the endoscope in posterior fossa approaches has been slower to be implemented and is used mainly as an adjunct to conventional microscopic surgical techniques. In this modern era, many neurosurgeons prefer using endoscopy during MVD either as a solo instrument (endoscopic MVD) or in combination with the microscope (endoscope-assisted MVD) [12-15]. Few neurosurgeons have applied the use of the endoscope for patients with vascu-

Shih-Shan Lang, MD

Hospital of the University of Pennsylvania, Department of Neurosurgery

3 Silverstein, 3400 Spruce Street

Philadelphia, PA 19104 (USA)

E-Mail shihshan.lang@uphs.upenn.edu 
lar lesions and tumors $[16,17]$. In this technique paper, we outline a step-by-step manner used at our institution for all patients undergoing endoscopic MVD for treatment of trigeminal neuralgia, hemifacial spasm or glossopharyneal neuralgia. We believe that this technical review can be helpful to neurosurgeons and ENT surgeons who are developing and/or self-evaluating their MVD technique.

\section{Patient Selection}

From January 2011 to December 2011, 104 patients were seen in the neurosurgery clinic for the diagnosis of trigeminal neuralgia or facial pain. A diagnosis of neurological facial pain $[18,19]$ consistent with trigeminal neuralgia was made by a single surgeon's expert opinion (J.Y.K.L.) utilizing the Burchiel classification system [20]. During this time frame, 29 craniotomies for MVD, 26 Gamma Knife ${ }^{\circledR}$ radiosurgery procedures [21], 1 Cyberknife ${ }^{\circledR}$ radiosurgery procedure and 5 percutaneous glycerol rhizotomies were performed. Of these patients who underwent a craniotomy for MVD, 21 were diagnosed with Burchiel type 1 classic trigeminal neuralgia and 8 patients were diagnosed with Burchiel type 2 trigeminal neuralgia. Of the craniotomies performed for MVD, 6 were microscope only, 6 were endoscope assisted and 17 were fully endoscopic. The endoscope-assisted procedures were performed as part of a gradual transition to a fully endoscopic procedure.

\section{Surgical Technique}

\section{Positioning}

All operations are performed under general endotracheal anesthesia. Prior to positioning the body (online suppl. video 1; for all online suppl. material, see www. karger.com/doi/10.1159/000342795), the patient's head is secured in a Mayfield 3-pin head clamp. We use the Mayfield clamp technique and positioning described by McLaughlin et al. [22]. The following landmarks should be noted prior to prepping: the tip of the mastoid process, the insertion of the digastric muscle, and the course of the sigmoid and transverse sinus as described by McLaughlin et al. [22] (fig. 1).

\section{Positioning the Pneumatic Holding Arm \\ Micromanipulator System}

Mitaka Kohki Co. (Tokyo) designs a pneumatically powered holding arm and endoscope adaptor (online suppl. video 2). The Mitaka pneumatic arm is firmly secured at the most cephalad aspect of the patient's bed. This often requires placing the arm board just inferior to

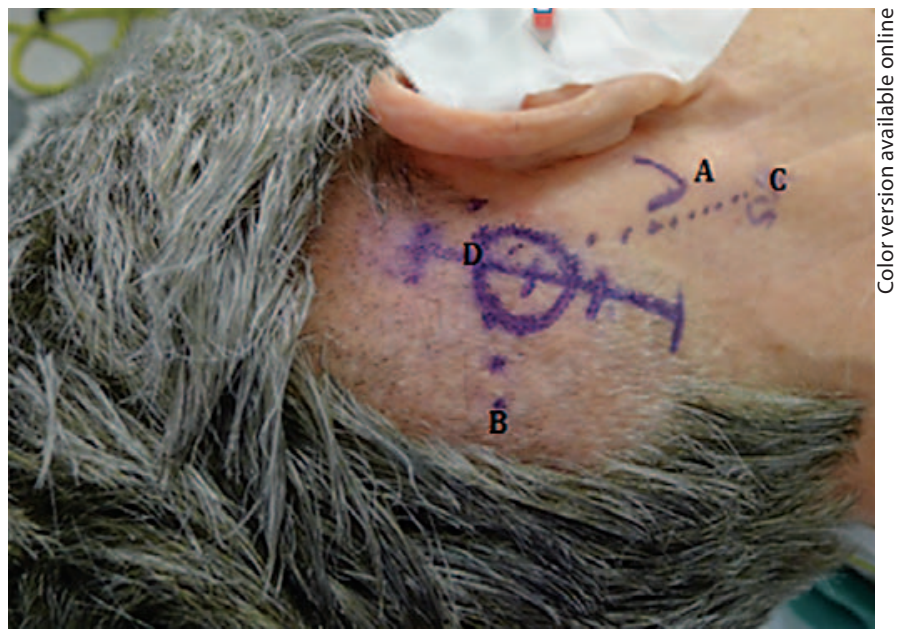

Fig. 1. Anatomical landmarks: the tip of the mastoid process (marked A), the inion-external meatus line. The course of the transverse sinus can be estimated by drawing a line from the inion to the external meatus (B, dotted line). An oblique line drawn on the posterior border of the mastoid process approximates the insertion of the digastric muscle and the course of the sigmoid sinus (C, dotted line). The posteroinferior quadrant of the intersection of these two lines is where the burr hole should be placed (D).

the Mitaka pneumatic arm attachment. The joints are then arranged in a figure 'four'. Through trial and error, we have determined that the optimal configuration of the figure 'four' is such that the last ball joint (distal ball joint) is directly over the proposed burr hole site (online suppl. video 2). Early in our experience we found the micromanipulator useful for fine adjustment, but we no longer use it. The pneumatic arm allows for quick adjustment of the position of the endoscope, but it is only balanced for its own weight. Thus, the addition of the endoscope and camera results in a small amount of 'sag' which must be compensated for during positioning.

\section{Skin Incision and Craniotomy}

The skin incision is linear, approximately $6 \mathrm{~cm}$ long just inferior to the junction of the transverse and sigmoid sinuses and approximately $1 \mathrm{~cm}$ behind the patient's hairline (online suppl. 3). The digastric notch is a useful bony anatomical landmark. The mastoid emissary vein is an inconsistent landmark. The burr hole for the craniotomy is centered just posterior to the most superior aspect of the insertion of the digastric muscle. The burr hole is performed with a standard perforator drill bit, and the 1.5$\mathrm{cm}$ diameter craniectomy is then expanded towards the sigmoid and transverse sinuses with a combination of 


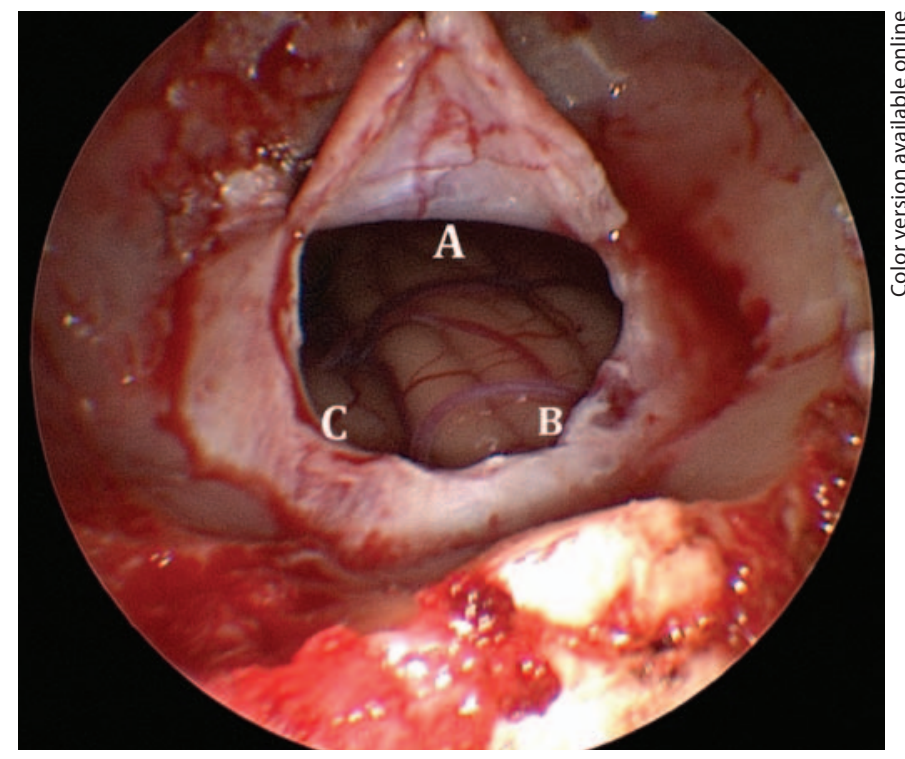

Fig. 2. Endoscopic view of dural opening. Placement of the endoscope at 12 o'clock (point A), microinstrument at 5 o'clock (B) and suction at 7 o'clock $(\mathrm{C})$.

a Kerrison rongeur and matchstick cutting burr. If any mastoid air cells are entered during drilling, bone wax is used to fill these air cells to prevent a cerebrospinal fluid (CSF) rhinorrhea.

\section{Dural Opening}

A C- or U-shaped incision is made in the dura mater, which is retracted anteriorly and reflected against the sinuses. This flap is suspended anteriorly by a stitch (fig. 2). At this point, the endoscope is brought in. Although other authors have described the use of a 4-mm outer diameter endoscope, we prefer to use the 2.7-mm 0-degree endoscope (Storz; Culver City, Calif., USA). This smallerdiameter endoscope maximizes the amount of working space that is needed for the other instruments, thus minimizing instrument conflict. In conjunction with a highdefinition camera, this system provides excellent visualization.

\section{Endoscope/Instrument Placement}

The placement of the endoscope, the suction and dissector should be arranged in a triangle to avoid the familiar 'sword clashing' seen in conventional endoscopic surgery (online suppl. video 2). The endoscope is kept at the apex of the triangle, and Fukushima variable control suction is used in the left hand with microinstruments in the right hand. This triangle can be thought of as clock posi-

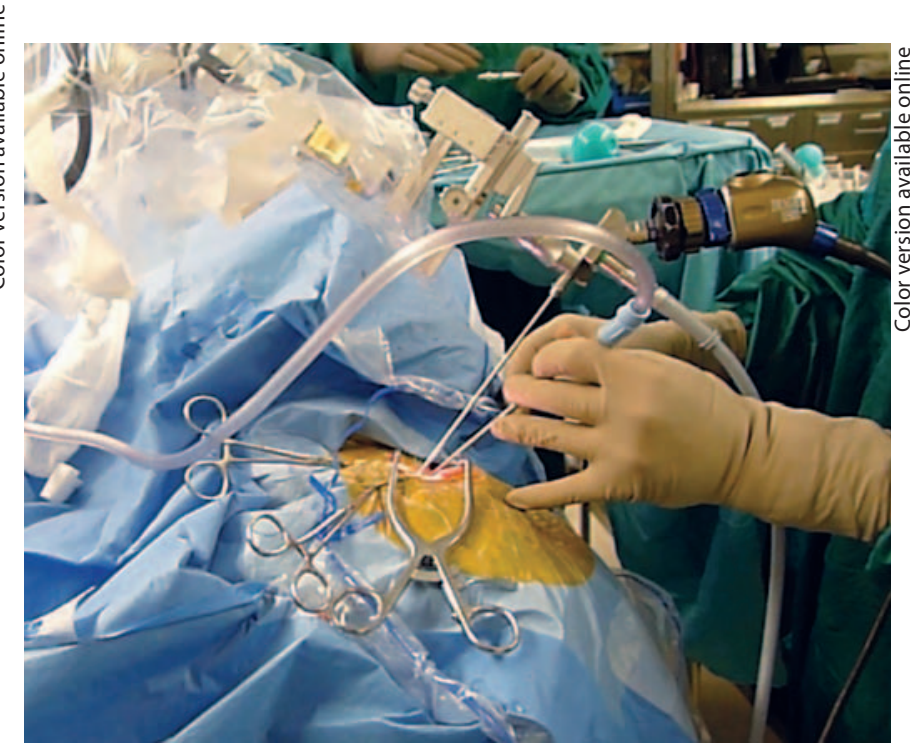

Fig. 3. Intraoperative view of instrument positioning in the configuration described in figure 7.

tions of 12 o'clock (endoscope), 5 o'clock (microinstrument) and 7 o'clock (suction) (fig. 2, 3). Storz ${ }^{\mathrm{TM}}$ Sephernia instruments are preferred for the majority of manipulation as they are designed for fine endoscopic work. If bipolarity is needed, conventional microbipolars, Storz 'take-apart endoscopic bipolar' or Aesculap ${ }^{\mathrm{TM}}$ pivot bipolars are used.

\section{Endoscopic MVD}

Next, the Duraprene ${ }^{\mathrm{TM}}$ glove and patty combination is introduced in an anteroinferior direction to protect the pial surface of the cerebellum (online suppl. video 4 ). The endoscope is guided along this path with minimal retraction on the cerebellum. The arachnoid sheath around the cranial nerve IX, X, XI bundle is dissected with sharp scissors. The CSF is slowly drained which allows the visualization of the cranial nerve IX, X, XI complex in the CPA (fig. 4).

The CPA can be divided anatomically through the endoscope into two zones separated by the acousticofacial bundle [9]. In this technique paper, we will concentrate on the superior zone above the acousticofacial bundle where the trigeminal nerve and Meckel's cavity can be explored. Using a combination of bipolar coagulation of minor vessels and blunt dissection, the arachnoid around the trigeminal nerve is lysed and the vascular anatomy around the trigeminal nerve can be inspected. 


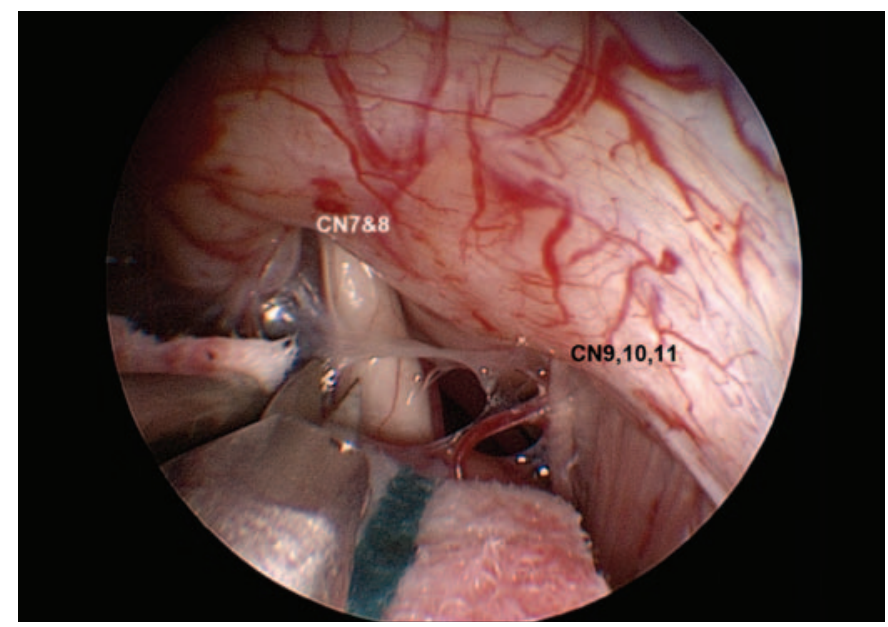

Fig. 4. Dissection of the arachnoid in order to visualize the cranial nerve IX, X, XI complex. CN 8 = Vestibulocochlear nerve.

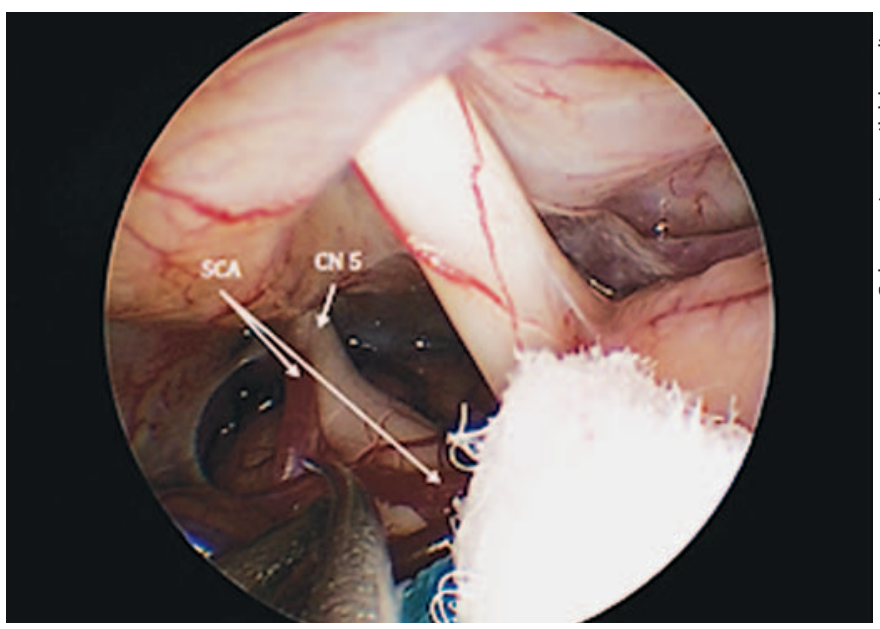

Fig. 6. The superior cerebellar artery (SCA) is the most common offending pathological vasculature; the trigeminal nerve (CN 5) is decompressed from the SCA by Teflon pads.

Figure 5 shows a view of the entire CPA and important anatomical structures. The offending vessel is mobilized by using a microdissector. MVD is achieved by placing a Teflon pad between the offending vessel and the trigeminal nerve.

A special note must be made regarding the choice of instruments within the narrow confines of the CPA. The surgeon must learn to work around the endoscope, often using techniques that have been borrowed from endonasal ventral skull base surgery. Because of the small space

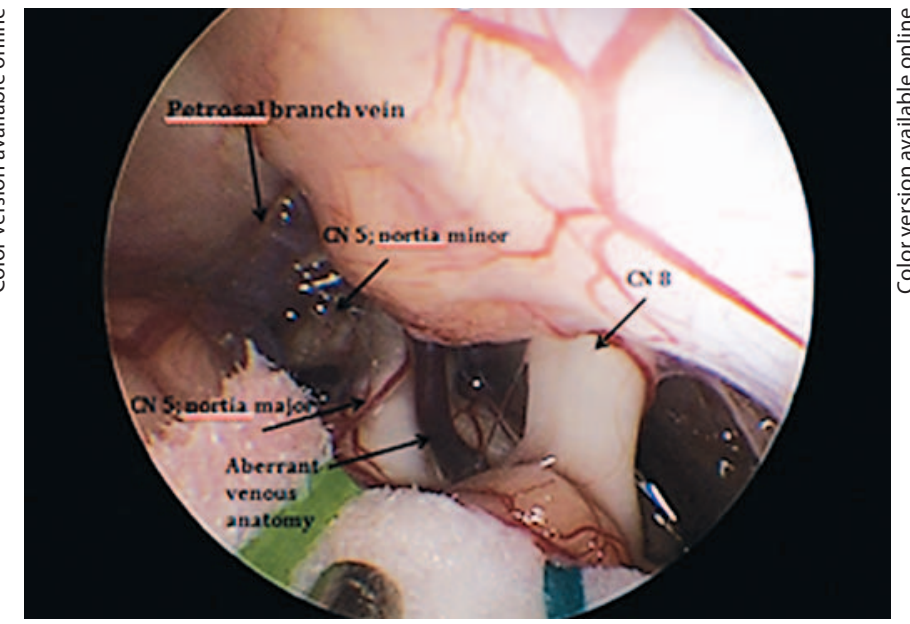

Fig. 5. View of the CPA will often show vascular pathology of the trigeminal nerve. In this case, the offending vascular structure was a complex of aberrant veins. CN $5=$ Trigeminal nerve; $\mathrm{CN}$ $8=$ vestibulocochlear nerve.

during opening and the fact that the center of the opening is occupied by the shaft of the endoscope, instruments are generally introduced into the CPA parallel to the endoscope. Hence, instruments curved gently at the tip are the most useful, such as the Sephernia microscissors. We have not found larger curves to be useful as it can become dangerous near multiple delicate vessels and nerves to use more aggressively curved instruments.

Use of angled endoscopes is another option in this procedure, and we have found the 30-degree endoscope to be the best compromise of maneuverability and improved visualization. When using the 30 -degree endoscope, the triangle concept of instrument placement continues to be useful for maximizing maneuverability. We have found the 30-degree endoscope to be the most useful to identify the anatomy between the 7th and 9th cranial nerves especially for hemifacial spasm and identification of the nervus intermedius for geniculate neuralgia.

\section{Illustrative Cases}

\section{Illustrative Case 1: Superior Cerebellar Artery Compression}

A 64-year-old female presented to the clinic with 5 years of right-sided facial pain mainly in the V2/V3 distribution. She was categorized as a case of Burchiel type 2 trigeminal neuralgia (online suppl. video 4). She underwent a retromastoid craniectomy and endoscopic MVD. Compression of the trigeminal nerve by the superior cer- 


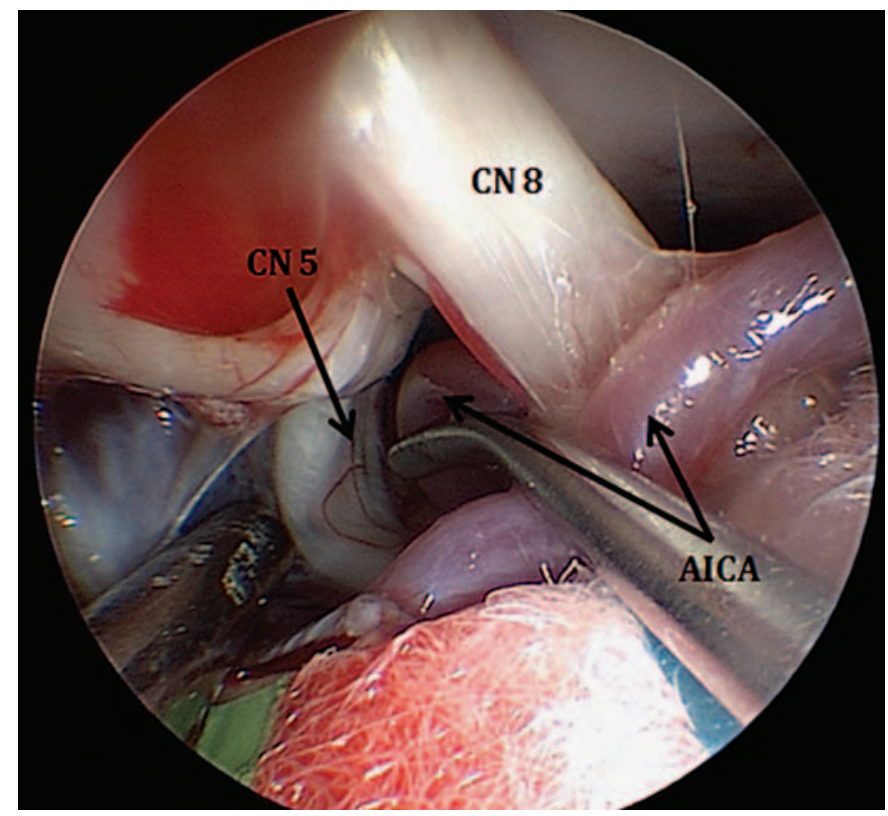

Fig. 7. Compression of the trigeminal nerve (CN 5) caused by the anterior inferior cerebellar artery (AICA). Note the deep indentation on the nerve from AICA compression. CN 8 = Vestibulocochlear nerve.

ebellar artery was seen and the nerve was decompressed without complications (fig. 6). On her 1-month postoperative clinic visit, she stated she had $100 \%$ improvement of her preoperative symptoms and was off all preoperative pain medications.

\section{Illustrative Case 2: Anterior Inferior Cerebellar Artery Compression}

In approximately a quarter of the cases of vascular compression causing trigeminal neuralgia, compression of the nerve is caused by the anterior inferior cerebellar artery $[23,24]$. In this case, a 62-year-old female had a 2-year history of right-sided V3 distribution, Burchiel type 2 trigeminal neuralgia. The patient underwent an endoscopic MVD and compression of the trigeminal nerve by the anterior inferior cerebellar artery was identified. Note the deep groove on the trigeminal nerve from compression by the artery (fig. 7). The patient had complete resolution of her preoperative pain.

\section{Closure}

Hemostasis is achieved and warm saline is injected into the CPA to compensate for the loss of CSF during the operation (online suppl. 5). The dura mater is meticu- lously sutured using 4-0 silk Nurolon ${ }^{\circledR}$ sutures. This closure can be supplemented with a local muscle or local fascial autograft to achieve a watertight closure. A small piece of Medtronic Dura Repair or Integra Duragen ${ }^{\circledR}$ is placed over the craniotomy defect. Gelfoam (Johnson \& Johnson) is placed to recapitulate the cancellous bone depth. One titanium mesh round the burr hole cover (Synthes) is used to protect the craniectomy defect. The muscle and galea aponeurosis layer is then approximated and closed with vicryl sutures, and the skin layer is closed with a running nylon suture.

\section{Conclusion}

In this paper, we provide our step-by-step approach to a purely endoscopic MVD. Endoscopic MVD is one of the many minimally invasive approaches to common operative procedures in neurosurgery today. The applications of the neuroendoscope are quickly escalating in neurosurgery and otological surgery, so it is vital that optimal surgical techniques are used. The expanding literature on endoscopic MVD supports the use of the endoscope as a tool that provides excellent results with a low rate of complications [6-8].

Endoscopic approaches to the posterior fossa demonstrate a sharp learning curve for the surgeon. The expansion of endoscopic MVD to other CPA vascular and tumor pathologies represents the next step in the era of minimally invasive surgery.

\section{Disclosure Statement}

S.-S.L.: none; H.I.C.: none; J.Y.K.L.: Baxter, speaker's bureau.

References

1 Dandy W: An operation for the cure of tic douloureux: partial section of the sensory root at the pons. Arch Surg 1929;18:687-734.

$\checkmark 2$ Dandy WE: The treatment of trigeminal neuralgia by the cerebellar route. Ann Surg 1932;96:787-795.

3 Gardner WJ, Miklos MV: Response of trigeminal neuralgia to decompression of sensory root: discussion of cause of trigeminal neuralgia. JAMA 1959;170:1773-1776.

4 Jannetta PJ: Observations on the etiology of trigeminal neuralgia, hemifacial spasm, acoustic nerve dysfunction and glossopharyngeal neuralgia. Definitive microsurgical treatment and results in 117 patients. Neurochirurgia (Stuttg) 1977;20:145-154. 
5 Magnan J, Chays A, Caces F, Lepetre C, Cohen JM, Belus JF, Bruzzo M: Contribution of endoscopy of the cerebellopontine angle by retrosigmoid approach. Neuroma and vasculo-nervous compression. Ann Otolaryngol Chir Cervicofac 1993;110:259-265.

$\checkmark 6$ Artz GJ, Hux FJ, Larouere MJ, Bojrab DI, Babu S, Pieper DR: Endoscopic vascular decompression. Otol Neurotol 2008;29:9951000 .

7 Teo C, Nakaji P, Mobbs RJ: Endoscope-assisted microvascular decompression for trigeminal neuralgia: technical case report. Neurosurgery 2006;59:ONSE489-490, discussion ONSE490.

$>8$ Jarrahy R, Eby JB, Cha ST, Shahinian HK: Fully endoscopic vascular decompression of the trigeminal nerve. Minim Invasive Neurosurg 2002;45:32-35.

9 Magnan JGH. Atlas of neurosurgical techniques; in Sekhar LN (ed): Endoscope-Assisted Microvascular Decompression. Stuttgart, Thieme, 2006.

$>10$ Jho HD, Carrau RL: Endoscopy assisted transsphenoidal surgery for pituitary adenoma. Technical note. Acta Neurochir (Wien) 1996;138:1416-1425.
11 Adappa ND, Learned KO, Palmer JN, Newman JG, Lee JY: Radiographic enhancement of the nasoseptal flap does not predict postoperative cerebrospinal fluid leaks in endoscopic skull base reconstruction. Laryngoscope 2012;122:1226-1234.

12 Ebner FH, Koerbel A, Kirschniak A, Roser F, Kaminsky J, Tatagiba M: Endoscope-assisted retrosigmoid intradural suprameatal approach to the middle fossa: anatomical and surgical considerations. Eur J Surg Oncol 2007;33:109-113.

13 Acerbi F, Broggi M, Gaini SM, Tschabitscher M: Microsurgical endoscopic-assisted retrosigmoid intradural suprameatal approach: anatomical considerations. J Neurosurg Sci 2010;54:55-63.

14 Schroeder HW, Oertel J, Gaab MR: Endoscope-assisted microsurgical resection of epidermoid tumors of the cerebellopontine angle. J Neurosurg 2004;101:227-232.

15 Schroeder HW, Hickmann AK, Baldauf J: Endoscope-assisted microsurgical resection of skull base meningiomas. Neurosurg Rev 2011;34:441-455

16 Shahinian HK, Eby JB, Ocon M: Fully endoscopic excision of vestibular schwannomas. Minim Invasive Neurosurg 2004;47:329332.

17 Shahinian HK, Ra Y: 527 fully endoscopic resections of vestibular schwannomas. Minim Invasive Neurosurg 2011;54:61-67.
18 Zakrzewska JM: Facial pain: neurological and non-neurological. J Neurol Neurosurg Psychiatry 2002;72(suppl 2):ii27-ii32.

19 Burchiel KJ: A new classification for facial pain. Neurosurgery 2003;53:1164-1166, discussion 1166-1167.

20 Lee JY, Chen HI, Urban C, Hojat A, Church E, Xie SX, Farrar JT: Development of and psychometric testing for the Brief Pain Inventory-Facial in patients with facial pain syndromes. J Neurosurg 2010;113:516-523.

21 Lee JYK, Moon JG, Kondziolka D, Flickinger JC, Lunsford LD: Gamma knife radiosurgery as the primary intervention for trigeminal neuralgia. Radiosurgery 2006;6:249-259.

22 McLaughlin MR, Jannetta PJ, Clyde BL, Subach BR, Comey CH, Resnick DK: Microvascular decompression of cranial nerves: lessons learned after 4,400 operations. J Neurosurg 1999;90:1-8.

23 Sindou M, Chiha M, Mertens P: Anatomical findings in microsurgical vascular decompression for trigeminal neuralgia. Correlations between topography of pain and site of the neuro-vascular conflict. Acta Neurochir Suppl 1995;64:125-127.

24 Uchino A, Hasuo K, Matsushima T, Tamura S, Yasumori K, Fukui M, Masuda K: Angiographic observations in idiopathic trigeminal neuralgia. Radiat Med 1988;6:12-16. 